\title{
Extinction risk and conservation gaps for Aloe (Asphodelaceae) in the Horn of Africa
}

\author{
Steven P. Bachman ${ }^{1,3}$ (D) Paul Wilkin ${ }^{1}$ (D) Tom Reader $^{2}$ (D) $\cdot$ Richard Field $^{3}$ (D) . \\ Odile Weber $^{4}$ (D) Inger Nordal ${ }^{5} \cdot$ Sebsebe Demissew ${ }^{1,6}$ (D)
}

Received: 22 March 2019 / Revised: 5 August 2019 / Accepted: 3 October 2019 /

Published online: 23 October 2019

(c) The Author(s) 2019

\begin{abstract}
Identification of conservation priorities is essential for conservation planning, especially as the biodiversity crisis develops. We aimed to support conservation prioritisation by addressing knowledge gaps for the genus Aloe in the Horn of Africa. Specifically, we developed a dataset of herbarium voucher specimens and occurrence data to estimate geographic distribution of 88 species of Aloe and used this to estimate extinction risk and establish the major threats to Aloe in this region. The resulting assessments, each published on the IUCN Red List, show that $39 \%$ of the species are threatened with extinction, and the principal threats are the expansion and intensification of crop farming and livestock farming, gathering of plants, and unintentional effects of logging and wood harvesting. We review ex situ conservation in botanic gardens and seed banks, revealing gaps in coverage and urgent priorities for collection, with 25 threatened Aloe species currently unrepresented in seed banks. Protected areas in the region offer limited coverage of Aloe distributions and the most recently designated protected areas are increasingly in regions that do not overlap with Aloe distributions. However, we show with a simple optimisation approach that even a modest increase in protected area of 824 square kilometres would allow representation of all Aloe species, although further data are needed to test the area required to ensure longterm persistence (resilience) of Aloe species.
\end{abstract}

Keywords Red List · IUCN · Protected areas · Threats

Communicated by Daniel Sanchez Mata.

Electronic supplementary material The online version of this article (https://doi.org/10.1007/s1053 1-019-01870-0) contains supplementary material, which is available to authorized users.

Steven P. Bachman

s.bachman@kew.org

Sebsebe Demissew

sebseb.demissew@gmail.com

Extended author information available on the last page of the article 


\section{Introduction}

Human alteration of landscapes (Venter et al. 2016), unsustainable use of wild species (Tierney et al. 2014), expansion and intensification of croplands (Kehoe et al. 2017) and increasing threats associated with a changing climate (Urban 2015) are all contributing factors to an ongoing biodiversity extinction crisis (Ceballos et al. 2015; Díaz et al. 2019). Loss of species affects ecosystem function and can reduce biomass production, reduce stability of ecosystems and cause irreversible changes or even ecosystem collapse (Hooper et al. 2012; Cardinale et al. 2012; Newbold et al. 2018). With current spending on conservation deemed insufficient and inadequately allocated to bring about a halt to the global biodiversity crisis (McCarthy et al. 2012; Waldron et al. 2013), a process of prioritising conservation effort is necessary.

Numerous global-scale approaches have been developed to identify species and sites of greatest importance for conservation (Brooks et al. 2006) -including biodiversity hotspots (Myers et al. 2000), Key Biodiversity Areas (IUCN 2016a), Alliance for Zero Extinction Sites (AZEs, Ricketts et al. 2005) and Important Plant Areas (Darbyshire et al. 2017) —as well as approaches that prioritise conservation based on other factors such as evolutionary history ( $\mathrm{Li}$ et al. 2018). Protecting these sites and associated species can be accomplished through the expansion of the protected area network (Butchart et al. 2012, 2015). This approach is consistent with global conservation targets such as the Convention on Biological Diversity's (CBD) Aichi Target 11 to conserve 17\% of terrestrial land that is '... of particular importance for biodiversity...' (UNEP/CBD 2010) and the Global Strategy for Plant Conservation (GSPC) Target 5 that aims to conserve 'At least 75 per cent of the most important areas for plant diversity...' (CBD 2010). These prioritisation approaches depend on high-quality biodiversity data such as species inventories, species distribution maps and estimates of species' extinction risk.

Historically, biodiversity data collection has been biased towards areas of relatively low diversity, away from the tropics (Collen et al. 2008). Despite growth in digitally accessible information (DAI), such as primary observation data held in museums and herbaria (Meyer et al. 2016; Le Bras et al. 2017), there are still major gaps in coverage that need to be addressed, particularly in emerging economies (Meyer et al. 2015). Insufficient data coverage and biased data can affect performance of algorithms to select protected area networks (Grand et al. 2007), although even limited data can provide valuable information for evaluating complementarity during protected area selection (Gaston and Rodrigues 2003). Furthermore, a potential cost of waiting too long for a 'complete' dataset is that opportunities for protection can be missed (Grantham et al. 2009). Gaps are also prevalent in specieslevel conservation products such as the IUCN Red List of Threatened Species (hereafter 'Red List'). The Red List is both a quantitative system to classify extinction risk under prevailing conditions (IUCN 2012) and a dataset of assessed species with extinction risk ratings and associated data (https://www.iucnredlist.org/). Although extinction risk of species should not be the sole consideration when prioritising conservation effort (Arponen 2012), it does reveal that we need to act urgently, in a way that is comparable across species; the Red List has been widely used in conservation prioritisation efforts (Hoffmann et al. 2008; Venter et al. 2014). Gaps in taxonomic coverage of the Red List include fungi (Dahlberg and Mueller 2011), invertebrates (Cardoso et al. 2011) and plants, the latter having only $\sim 9 \%$ of species assessed and published on the IUCN Red List (McBride et al. 2012). Recognising these gaps, calls have been made to treble the representation of plants on the list from 2009 levels to nearly 40,000 species (Stuart et al. 2010). In response, some gaps have 
been filled with comprehensive assessment of charismatic plant groups such as cacti (Goettsch et al. 2015) and ongoing assessment of thematic groups such as trees (Rivers 2017), but most plant species have yet to be assessed and published on the Red List.

The Horn of Africa represents a target for addressing the baseline biodiversity and conservation data gaps already highlighted. The Horn of Africa is an area of global significance for biodiversity, with three biodiversity hotspots represented in the region (Horn of Africa, Eastern Afromontane, and Coastal forests of Eastern Africa; Mittermeier et al. 2004), and countries in this region have reported the need for baseline data as part of National Biodiversity Strategy and Action Plans (Ethiopian Biodiveristy Institue 2015; Ullah and Gadain 2016). Here, we focus on Aloe L. (Asphodelaceae subf. Asphodeloideae), an iconic and economically important succulent plant genus that exhibits high diversity in this region; we explore extinction risk, threats and conservation gaps.

The genus Aloe extends across Sub-Saharan Africa and reaches into the Arabian Peninsula. The regions of highest species richness are in southern and eastern Africa, including Madagascar and the Horn of Africa - all areas that coincide with biodiversity hotspots (Mittermeier et al. 2004) (Fig. 1). Aloe species play an important role in supporting local livelihoods across their distribution range, with documented uses for medicine, foods and as ornamental plants (Demissew and Nordal 2010; Grace 2011; Amir et al. 2019). Local

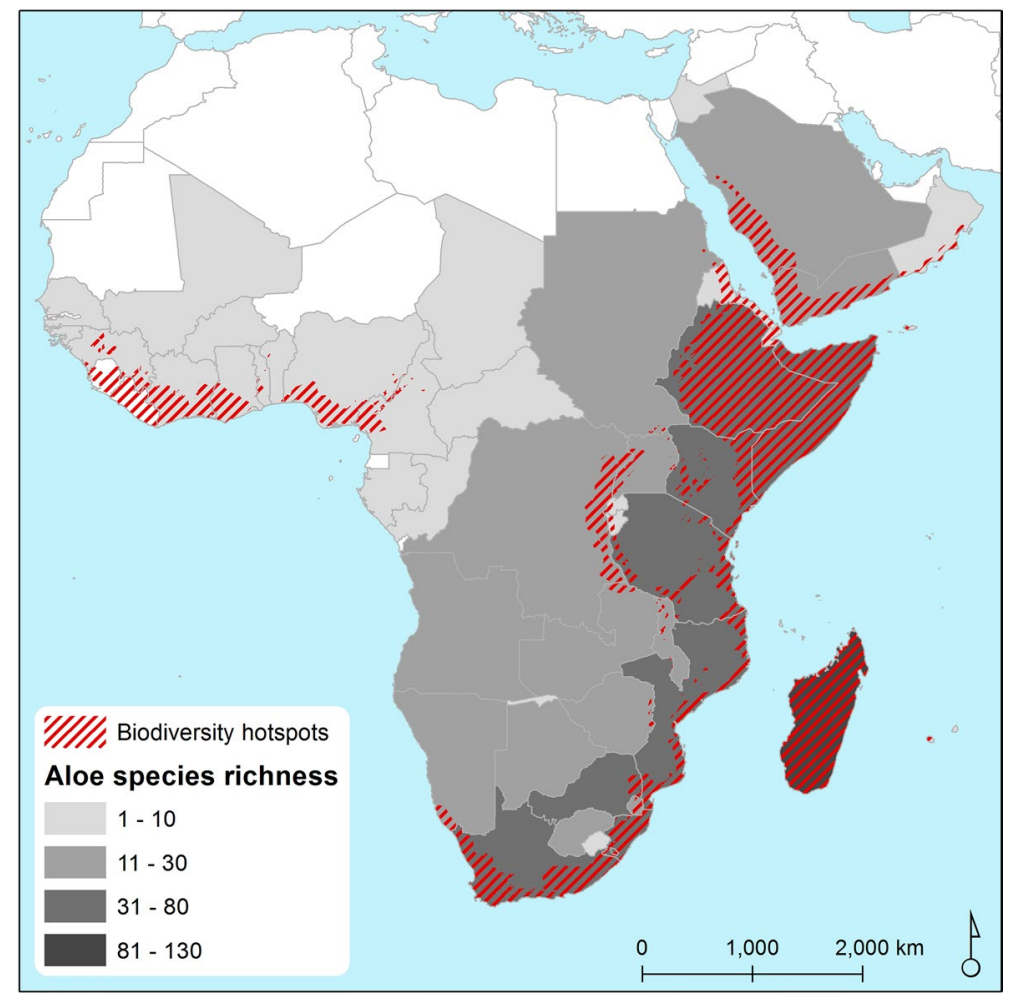

Fig. 1 Native distribution of the genus Aloe according to the World Checklist of Selected Plant Families (WCSP) using the Taxonomic Database Working Group geopolitical regions at level 3 (WCSP 2013). Richness of Aloe species is shown in conjunction with the 'biodiversity hotspots' (red hatched lines) sensu Mittermeier et al. (2004) 
harvesting has been reported to be non-detrimental to populations in some areas (Bjorå et al. 2015), but commercial demand for succulent plants like Aloe has caused declines that have led to their listing on the Convention on International Trade in Endangered Species (CITES) to help ensure that trade does not threaten their survival (CITES-Secretariat 2016). Despite these measures, illegal harvesting of wild Aloe persists, as does the threat of habitat conversion for agriculture (Darkoh 2003).

Progress in assessing the extinction risk of the estimated 630 Aloe species (Klopper et al. 2013) has been slow, with only 43 (7\%) having published assessments by the time of the 2010 update of the IUCN Red List. Assessments have been made through regional initiatives including the Red List of South African Plants (Raimondo et al. 2009). Of the 128 Aloe taxa assessed for the Red List of South African Plants, 20\% were listed as threatened and a further $8 \%$ were listed as either 'Rare' or 'Declining'. In Madagascar, a preliminary assessment using the latest IUCN categories and criteria classified 39\% of species as being threatened with extinction, although half were regarded as having insufficient data to assess (Rakotoarisoa et al. 2014). A preliminary Red List assessment of 25 endemic Kenyan Aloe taxa showed $80 \%$ were classified as threatened (Wabuyele et al. 2006). Plants across Eastern Africa are being targeted for assessment by the Eastern African Plant Red List Authority (EAPRLA) (Luke et al. 2014) and good progress is being made with over 2400 taxa assessed to date (H. Beentje pers. comm. 2017). EAPRLA have assessed 28 Aloe species to date, of which $70 \%$ were classified as threatened (H. Beentje pers. comm. 2017). Prior to the present study, the only region with high Aloe species richness that is yet to receive assessment of extinction risk within the genus is the Horn of Africa.

Our aim was to address conservation knowledge gaps for Aloe in the Horn of Africa and to explore opportunities for prioritising future conservation efforts. We established a baseline dataset of Aloe occurrences and used this to underpin an assessment of extinction risk using the IUCN Red List categories and criteria (IUCN 2012). We used the IUCN Red List Threats Classification Scheme (version 3.2), based on Salafsky et al. (2008), to identify the threatening processes acting on Aloe occurring in the Horn of Africa region. We then identified current gaps in conservation coverage for Aloe, both in terms of the storage of genetic material ex situ (i.e. representation in seed banks and botanic gardens), as well as in situ, in the form of representation of wild populations in the protected area network. We then developed an algorithm to explore scenarios to efficiently grow the protected area network, in order to represent part of every Aloe distribution in this region.

\section{Methods}

\section{Study area}

Our study includes all species of Aloe that occur in, but are not necessarily endemic to, the Horn of Africa region. We define the Horn of Africa to include Djibouti, Eritrea, Ethiopia, Somalia, Sudan and South Sudan, covering a combined area of 4,388,570 km² (Fig. 2a). Sudan and South Sudan would not normally be classified as Horn of Africa, but were included to account for several Aloe species endemic to the Imatong mountain range. The majority of Sudan and South Sudan is not thought to contain any other Aloe species (Darbyshire et al. 2015). The study area overlaps the Eastern Afromontane, Coastal Forest of Eastern Africa and Horn of Africa biodiversity hotspots (Mittermeier et al. 2004). Somalia, Djibouti and parts of Eritrea and Ethiopia are characterised by high aridity. The central 


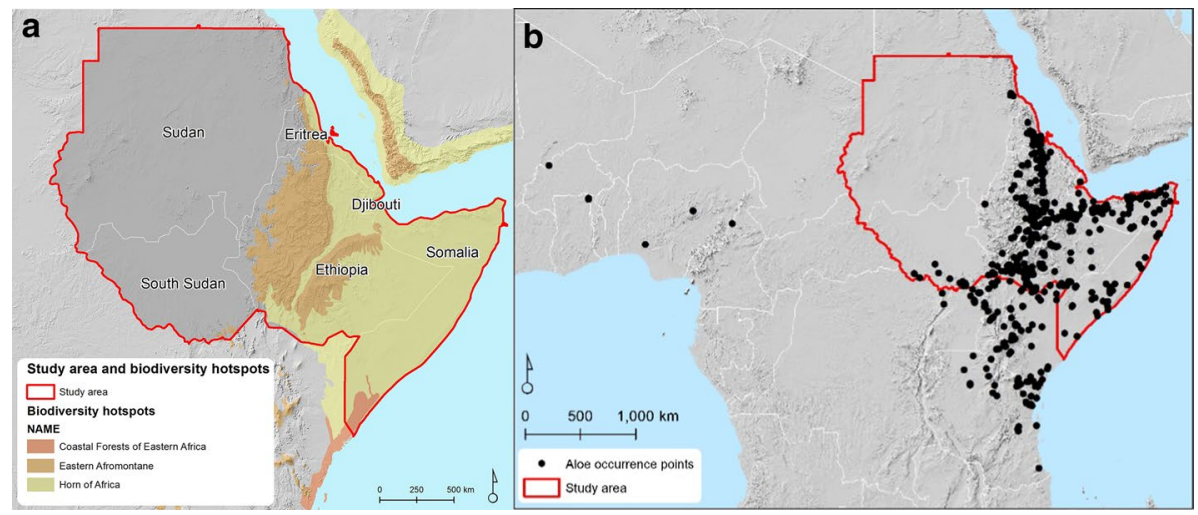

Fig. 2 Study area from which all Aloe species were selected for inclusion in the analysis (a). Each species had to occur in the study area (red boundary), but occurrence data for some species spread outside the study area $(\mathbf{b})$

highlands of Ethiopia, with peaks reaching $4000 \mathrm{~m}$, are separated by the Rift Valley and have a more temperate climate, and a diversity of vegetation types (Lilles $\varnothing$ et al. 2011). The diversity in climate and elevation in this region has led, over time, to richness in plant life forms and taxa.

\section{Aloe occurrence data}

Global geographic ranges of Aloe species from the Horn of Africa study area were estimated from a database of herbarium voucher specimens. We compiled the database after consulting the literature and the following herbaria: The Natural History Museum, UK (BM); University of Copenhagen, Denmark (C); Herbarium, Dar es Salaam, Tanzania (DSM); National Museums of Kenya, Kenya (EA); Addis Ababa University, Ethiopia (ETH); Centro Studi Erbario Tropicale, Università degli Studi di Firenze, Italy (FT); Royal Botanic Gardens, Kew, UK (K); Botanical Museum, University of Oslo, Norway (O); Museum of Evolution, Uppsala, Sweden (UPS); South African National Biodiversity Institute, South Africa (PRE); Harare Botanic Garden, Zimbabwe (SRGH), and Naturalis, Netherlands (WAG). Herbarium codes follow Thiers (2015). One of us (Demissew) verified the identity of each specimen.

Where geographical co-ordinates were reported on specimen labels, these were manually checked for typos or obvious errors (e.g. where latitude and longitude were switched). Where co-ordinates were not given, each specimen was georeferenced post-facto from the textual description of the locality derived from the label. Each specimen was assigned a geographic co-ordinate pair using a variety of online gazetteers such as Fuzzy Gazetteer (http://dma.jrc.it/services/fuzzyg/) and GeoNames (http://geonames.nga.mil/namesgaz/), as well as mapping tools such as Google Earth (https://www.google.com/earth/) and historical paper maps. Specimens that did not contain sufficient information to assign co-ordinates (e.g. those only recorded to country or province level) were not included in the spatial analysis. After removing duplicate records, the final clean dataset comprised 711 occurrence records, representing 88 species with a mean of 8 occurrences per species. Fieldwork by Demissew and collaborators in Ethiopia has targeted under-sampled areas and has 
supplemented historical herbarium records, thereby improving both spatial and temporal coverage.

Subsequent to the initial data collection and analysis, a number of additional Aloe names were found in the literature. These names are mostly recent discoveries and are often represented by only one or two specimen collections from single locations. As we have not been able to examine these materials, and the descriptions are not sufficient to separate these names from existing species, we have not included them in this analysis. For the full list of excluded names see the Table A1 in the Supplementary Material.

\section{Red List assessment}

To assess the global Red List status of all 88 Aloe species occurring in the Horn of Africa study area, we adopted a semi-automated approach that combines spatial analysis of occurrence data with expert knowledge (Wilkin et al. 2013; Rakotoarinivo et al. 2014; Brummitt et al. 2015). We used our database of occurrences to calculate two metrics relating to geographic range used in IUCN Red List criterion B for all 88 species: extent of occurrence (EOO) and area of occupancy (AOO). In line with current IUCN guidelines, we calculated EOO in $\mathrm{km}^{2}$ from the minimum convex polygon (MCP) of all occurrence records thought to represent extant populations. We assumed that historical occurrences represented extant populations unless there was evidence to the contrary, such as the combination of habitat loss and no recent collections from the same area. The MCPs were calculated using the Conservation Assessment Tools (CATs) extension for ArcView GIS (Moat 2007) and the web application GeoCAT (Bachman et al. 2011). They did not exclude unsuitable habitat within the extent of the MCP (IUCN Standards and Petitions Subcommittee 2014; Joppa et al. 2016). For AOO, our approach was to overlay the occurrence data with a grid at the reference scale of $2 \mathrm{~km} \times 2 \mathrm{~km}$ cells (thus each cell was $4 \mathrm{~km}^{2}$ ), count the number of occupied cells and multiply by the area of the cells (IUCN 2012).

As few as 15 georeferenced occurrence records per species have been shown to be sufficient to correctly classify conservation status for $95 \%$ of species, and to achieve confidence in EOO and AOO calculations (Rivers et al. 2011). However, most of the species in our dataset have fewer than 15 georeferenced specimens (Fig. 3). To minimise the potential inaccuracy of EOO and AOO calculations resulting from this, expert knowledge gained from extensive field surveys in the region was used to fill gaps in occurrence data coverage. We reviewed the EOO and AOO range estimates for each species and adjusted them in cases where we know there are extant populations that are not represented by specimens in our database. Uncertainty was recorded as minimum and maximum values for EOO and $\mathrm{AOO}$, with maximum values incorporating further adjustments based on knowledge of habitat preferences and elevation ranges of Aloe species. The EOO and AOO estimates were further refined by expert review during the Red List assessment review stage (see below) and the method of calculation for each species is documented in Table A2 in the Supplementary Data.

The EOO and AOO values formed the basis of an assessment using IUCN Red List criterion B (restricted geographic ranges), but additional sub-criteria need to be met in order to complete a full assessment. We used the geographic range data and expert knowledge of threats in the region to estimate the number of threat-defined locations for each species and whether or not there was evidence for a continuing decline in any of the following: (i) extent of occurrence; (ii) area of occupancy; (iii) area, extent and/or quality of habitat; (iv) number of locations or subpopulations; (v) number of mature individuals (IUCN 


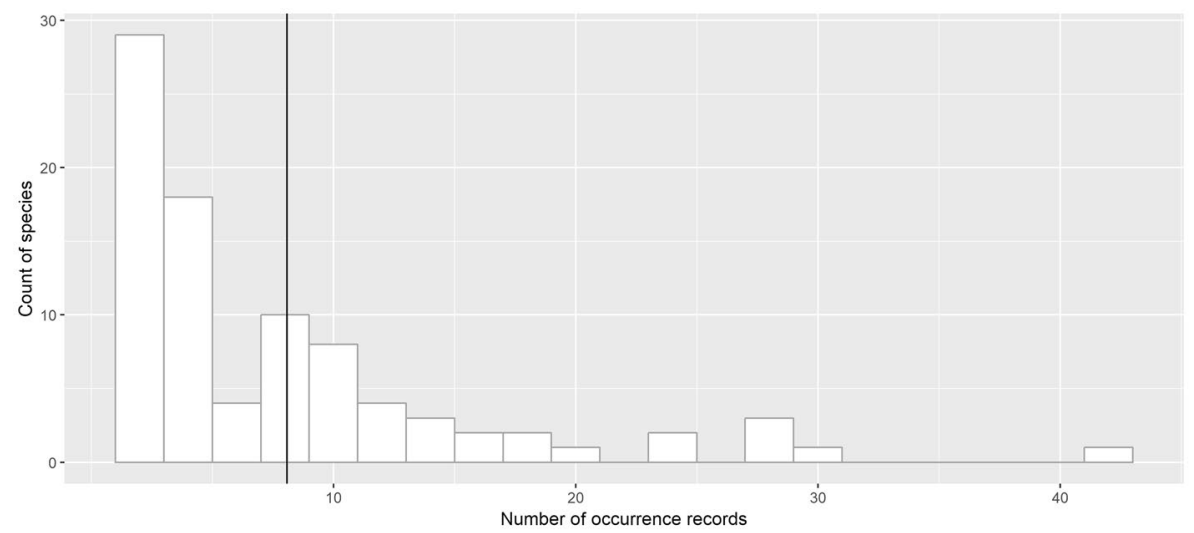

Fig. 3 Distribution of species according to number of occurrence records (number of occurrence records $=711$, number of species $=88$, mean occurrence records per species (solid black vertical line $=8.07)$

2012). We also considered all other Red List criteria A, C, D and E, but insufficient data on population size or trends in populations over time were available to apply these criteria for most species. The exception was A. cremnophila, which was assessed using criterion $\mathrm{D}$ as population size was estimated. The full Red List criteria are provided in Table A3 in the Supplementary Data. Once we had finished each assessment and determined the Red List rating, we entered the required data into the IUCN SIS data management system (https ://sis.iucnsis.org). All assessments were then reviewed by the East African Plant Red List Authority (EAPRLA) and the Red List Unit (Cambridge, UK). Once final modifications had been made, based on comments received through the review process, we re-submitted the assessments and supporting distribution maps for publication on the Red List website (www.iucnredlist.org). Our assessments have thus become part of the Red List.

\section{Classification of threatening processes}

Specimen label data, literature searching and expert judgement were used to code threats to each species using Threats Classification Scheme Version 3.2 (see Table A4 in the Supplementary Data for the full scheme). Threats to species were coded to the lowest level in the hierarchical classification scheme (e.g. 2. Agriculture and aquaculture $>2.3$. Livestock farming and ranching $>$ 2.3.2. Small-holder grazing, ranching or farming). Where species were affected by more than one threatening process, each threat was coded.

\section{Coincidence of protected areas and Horn of Africa Aloes}

We investigated the patterns and trends in protected area (PA) coverage in relation to the ranges of Aloe species occurring in the Horn of Africa. For this, and all further analysis, we used our Aloe point occurrence data as the basis for Aloe distribution ranges, which do not include the input of expert knowledge. Although expert knowledge was incorporated for EOO and AOO estimation, it was not mapped; therefore only the point occurrence data were used for analysis. 
For protected areas we used the World Database on Protected Areas (WDPA) dataset (UNEP-WCMC and IUCN 2018), which was subset to the following countries that coincide with Horn of Africa Aloe distributions: Democratic Republic of the Congo, Djibouti, Eritrea, Ethiopia, Kenya, Nigeria, Somalia, South Sudan, Sudan, Tanzania, Togo and Uganda. Protected areas were not clipped to country boundaries. We excluded all PAs that were not coded as 'designated', did not have a designation year and/or did not have a reported area. WDPA protected areas are mapped with polygons and points; points are used when the PA boundary has not been formally determined. To enable spatial analysis of PAs and Aloe distributions, a circular buffer was generated around each PA point, equal to the size of the reported area of the PA. The polygon layer represented the minimum PA coverage and merging the polygon layer with the buffered point layer produced the maximum PA coverage.

To determine the number of Aloe species with ranges overlapping the PA network, and how this has changed over time, we buffered the Aloe point distributions for each species and intersected the buffered range with the PA network. We explored the impact of different buffer distances $(2 \mathrm{~km}, 5 \mathrm{~km}, 10 \mathrm{~km}$ and $20 \mathrm{~km})$ on overall results and compared them with published recommendations (Di Marco et al. 2017). We assumed the points represented stable populations over time and compared this with the PA network as it changed over time. We intersected the buffered point distributions with the PA network at each year where PA data were available. We also determined the extent to which Aloe species ranges overlap the PA network (proportion of range as derived from the 2, 5, 10 and $20 \mathrm{~km}$ buffers, respectively).

\section{Extending the protected area network}

To explore how the PA network could be extended to ensure that each species of Aloe is represented in a PA, we developed a simple 'greedy algorithm' (Fig. 4). The algorithm was designed to select a set of unprotected patches that represents all species in the smallest possible area. To do this, the entire Aloe occurrence dataset was buffered by $2 \mathrm{~km}$ and dissolved so that the overlapping buffers were merged into unique 'patches' of varying shapes and areas. We then identified the species that occurred in each patch. Then we identified patches that were completely contained within the current (2018) PA network and labelled these as protected patches. We labelled any species that occurred within a protected patch as protected. The remaining unprotected patches were analysed using the greedy algorithm to find the patch with the highest number of unprotected species. These species were then labelled as protected (representing adding this patch to the PA network). The algorithm repeated this process by finding the next patch with the highest number of species not included in the previous set of patches until all species are accounted for. When two patches had the joint highest number of species, one patch was randomly selected, meaning each iteration of the algorithm could have returned a different solution. The sum of patch area was reported after each iteration of the algorithm, but because of the random patch selection when patches had joint highest number of species, different iterations may produce a different minimum area. We tested how many iterations were needed to achieve the minimum total patch area. It was necessary to run the algorithm for 500 iterations to achieve a minimum value that was within $1 \mathrm{~km}$ of a minimum calculated based on 1000 iterations. (see Fig. A5 in the Supplementary Data). We ran the algorithm 1000 times with the target of achieving at least one patch protected for all species in the smallest area. We ran the algorithm separately for all species, and a combined subset of threatened and data deficient species. For the most area-efficient solution, we noted the full 


\begin{tabular}{|c|c|}
\hline Patch & Species \\
\hline 1 & A, B, C \\
\hline 2 & A, C, D, E \\
\hline 3 & B \\
\hline 4 & E, F, G \\
\hline Algorithm & $\begin{array}{c}\text { Number of } \\
\text { step }\end{array}$ \\
\hline 1 & $\begin{array}{c}\text { Protected } \\
\text { species }\end{array}$ \\
\hline 2 & (A, C, D, E) \\
\hline 3 & 1 (F, G) \\
\hline
\end{tabular}

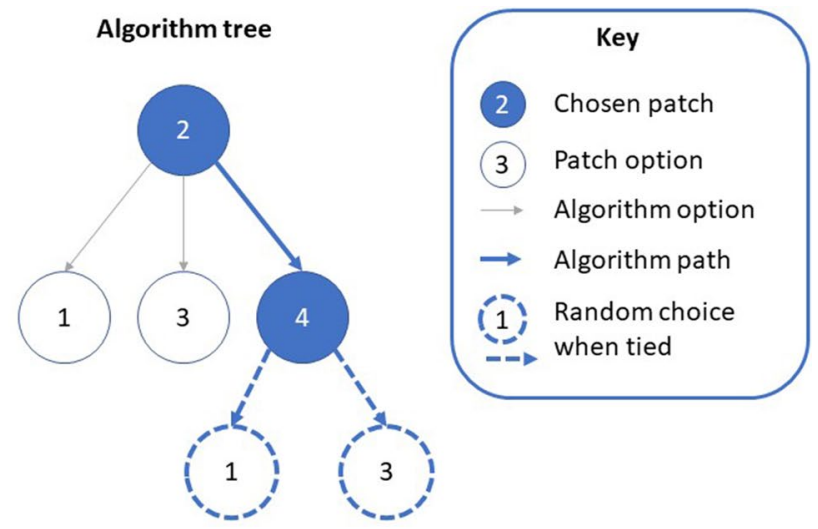

Fig. 4 Diagram to illustrate the greedy algorithm used to estimate the additional protected areas required to mean that all species of Aloe in the region are protected in at least part of their distribution. The patch with the highest number of species is selected first, in this example patch 2, which contains 4 species: A, $\mathrm{C}, \mathrm{D}$ and $\mathrm{E}$. The next patch is selected based on the highest number of species that have not already been included in patch 2, which is patch 4, containing species E, F and G. Only 2 new species are added because species $\mathrm{E}$ was already included in patch 2 . The algorithm then needs to decide on the final patch from a choice of patch 1 or patch 3. Both patches have an equal number of one new species to add (species B), so a random selection is made

sequence of sites (see Table A6a and A6b in the supplementary information for all species and combined threatened and data deficient species, respectively) and mapped these.

\section{Conservation collections in seed banks and botanic gardens}

Finally, we explored the level of ex situ conservation that Aloe species in the Horn of Africa were receiving. We queried the Botanic Gardens Conservation International (BGCI) PlantSearch database (https://www.bgci.org/plant_search.php) to determine how many collections of Aloe from the Horn of Africa there are across botanic gardens globally and if there is any difference in preference for threatened versus non-threatened Aloes. Similarly, we queried the Millennium Seed Bank base list (http://brahmsonline.kew.org/msbp/SeedData/BaseLists) to see how many Aloe species from the Horn of Africa have been seed-collected and, again, whether there was any preference for threatened versus non-threatened species.

All analysis was performed in ArcGIS or R (R Core Team 2016; ESRI 2017) and further detail is provided in supplementary methods, along with $\mathrm{R}$ code to reproduce the analysis at: https://github.com/stevenpbachman/Aloes_Horn_Diversity.

\section{Results}

\section{Extinction risk of Aloes based on IUCN Red List assessments}

Our assessment of Aloe from the Horn of Africa documented Red List status for 88 species, for which our best estimate is that $39 \%$ are threatened with a high risk of extinction (i.e. in 
the categories of Critically Endangered, Endangered or Vulnerable). Most of these are in the Endangered category (Table 1). The 'best' estimate assumes Data Deficient species are as threatened as data sufficient species; the plausible lower limit (where all DD species are assumed not to be threatened) is $35 \%$. In the context of other recent assessments of plant taxa, this puts Aloe in the Horn of Africa at higher risk than the global average for plants of (21\%) (Brummitt et al. 2015), cacti (31\%) (Goettsch et al. 2015) and conifers (34\%) (IUCN 2016b), but not as threatened as cycads (63\%) (IUCN 2016b). The listing of nearly $10 \%$ of species in the Data Deficient category means that there is uncertainty about the best estimate of percentage of species that are threatened. The upper estimate of percentage threatened, where all DD species are assumed to be in threatened categories, is that as many as $45 \%$ of the Aloe are threatened (Table 1). Most of the species classed as threatened (96\%) were classified according to criterion B1 (restricted extent of occurrence) or a combination of B1 and B2 (restricted area of occupancy), with just two species listed strictly based on AOO and one species listed under criterion D (small population size). For full listings of Red List assessments per species, see Table A2 in the supplementary material.

\section{Threats to Aloe in the Horn of Africa}

The principal threats to Aloe species are the expansion and intensification of crop farming and livestock farming (Fig. 5). Major threats are also posed by the gathering of plants, and unintentional effects of logging and wood harvesting. All species categorised as Critically Endangered are affected by at least one of these threatening processes. Livestock farming is the most frequently listed threat for threatened species. The gathering of plants is predominantly a threat when the species is the target (i.e. harvesting Aloe species directly from the wild). The unintentional effects of logging and wood harvesting are when there has been cutting and charcoal burning and disturbance to the habitat which has caused degradation and mortality to Aloe populations. Other threats include the ongoing expansion of urban areas and the direct and indirect effects of fire, as well as climate-related processes such as drought.

Table 1 Summary of final Red List assessment ratings for 88 assessed Aloes

\begin{tabular}{llll}
\hline Category & $\begin{array}{l}\text { Count of } \\
\text { species }\end{array}$ & Percentage & Method \\
\hline Critically endangered (CR) & 4 & $5 \%$ & Sum of CR \\
Endangered (EN) & 22 & $25 \%$ & Sum of EN \\
Vulnerable (VU) & 5 & $6 \%$ & Sum of VU \\
Lower estimate \% threatened & - & $35 \%$ & $(\mathrm{CR}+\mathrm{EN}+\mathrm{VU}) /($ total assessed) \\
Best estimate \% threatened & - & $\mathbf{3 9 \%}$ & $(\mathbf{C R}+\mathbf{E N}+\mathbf{V U}) /($ total assessed - DD) \\
Upper estimate \% threatened & - & $45 \%$ & $(\mathrm{CR}+\mathrm{EN}+\mathrm{VU}+\mathrm{DD}) /($ total assessed) \\
Near threatened (NT) & 9 & $10 \%$ & Sum of NT \\
Least concern (LC) & 39 & $44 \%$ & Sum of LC \\
Data deficient (DD) & 9 & $10 \%$ & Sum of DD \\
Total assessed & 88 & & CR +EN + VU + NT + LC+ DD \\
\hline
\end{tabular}

The best estimate for the percentage of species threatened (accounting for DD species) is 39\% (highlighted in the table) but could be as high as $45 \%$ if all species presently rated as DD were eventually assessed as threatened 


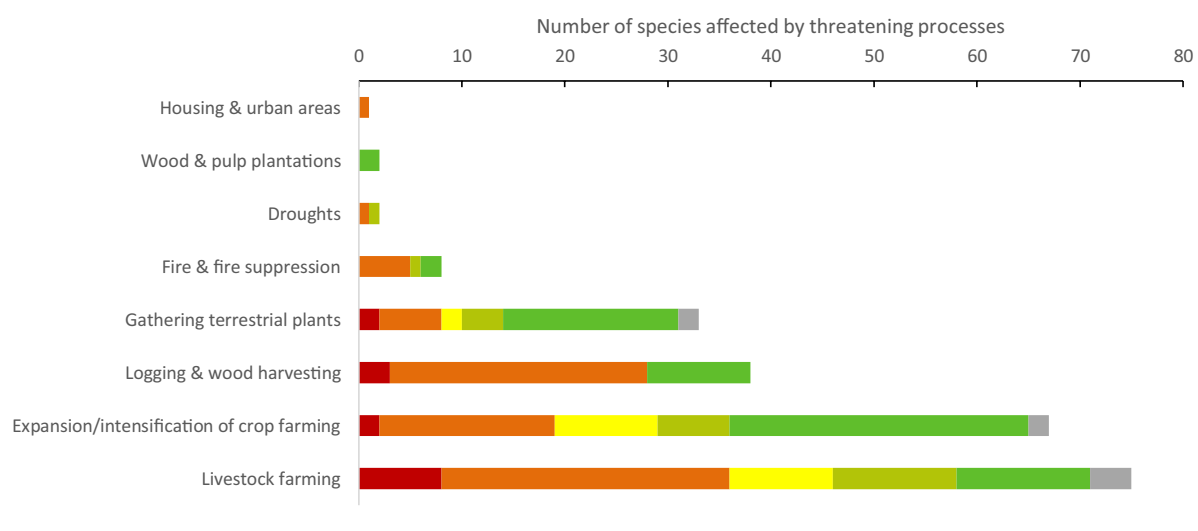

Fig. 5 Importance of different threatening processes affecting Aloe species. Number of species affected by each threat are broken down by IUCN Red List category. Threat classification follows IUCN Red List threat classification scheme version 3.2 with some modifications to labels. The IUCN threat codes for each labels are: livestock farming $=2.3,2.3 .1,2.3 .2$; expansion/intensification of crop farming $=2.1 .1,2.1 .2,2.1 .3$, 2.1.4; logging and wood harvesting $=5.3,5.3 .1,5.3 .2,5.3 .3,5.3 .4$; gathering terrestrial plants $=5.2,5.2 .1$, 5.2.3; fire and fire suppression $=7.1,7.3,7.1 .1,7.1 .3$; droughts $=11.2$; wood and pulp plantations $=2.2$, 2.2.1; housing and urban areas $=1.1$

\section{Coincidence of protected areas and Horn of Africa Aloe distributions}

Protected areas in the countries where Horn of Africa Aloe species occur were first established in 1905 and have grown steadily until the present day, aside from the early 1970s when there was a spike in growth of PA coverage (Fig. 6a). However, the recent growth in PAs has occurred in areas that do not overlap with Aloe distributions, and this pattern is especially apparent for threatened species: no additional threatened species have been included in PA coverage since the mid-1970s (Fig. 6b). A similar pattern is shown when considering the proportion of Aloe species ranges receiving protection (Fig. 7). Most species ranges are not covered by any PA and the proportion of species with $>1 \%$ of the range protected has changed little since the mid-1970s. Only $\sim 5 \%$ of Aloe species have at least half of their ranges protected under the current PA network.

Buffer size between 2 and $10 \mathrm{~km}$ did not substantially influence the number of species covered by PAs, but a marked change occurred at $20 \mathrm{~km}$ (Fig. 6b). To avoid commission errors when exploring options to grow the PA network, we adopted the lowest buffer size of $2 \mathrm{~km}$.

\section{Options to extend the PA network to cover all Aloe species}

The Aloe distributions were buffered and merged to produce 528 unique patches (shown as dots on Fig. 8), of which 50 are already completely within the PA network. The best scenario of the greedy algorithm - the one that required protection of the smallest total area-required 45 patches to be added to the PA network, these new patches totalling $824 \mathrm{~km}^{2}$ (Table A6a in Supplementary Data). The first ten patches are identified in Fig. 8a. Running the same algorithm on the combined threatened and Data Deficient 


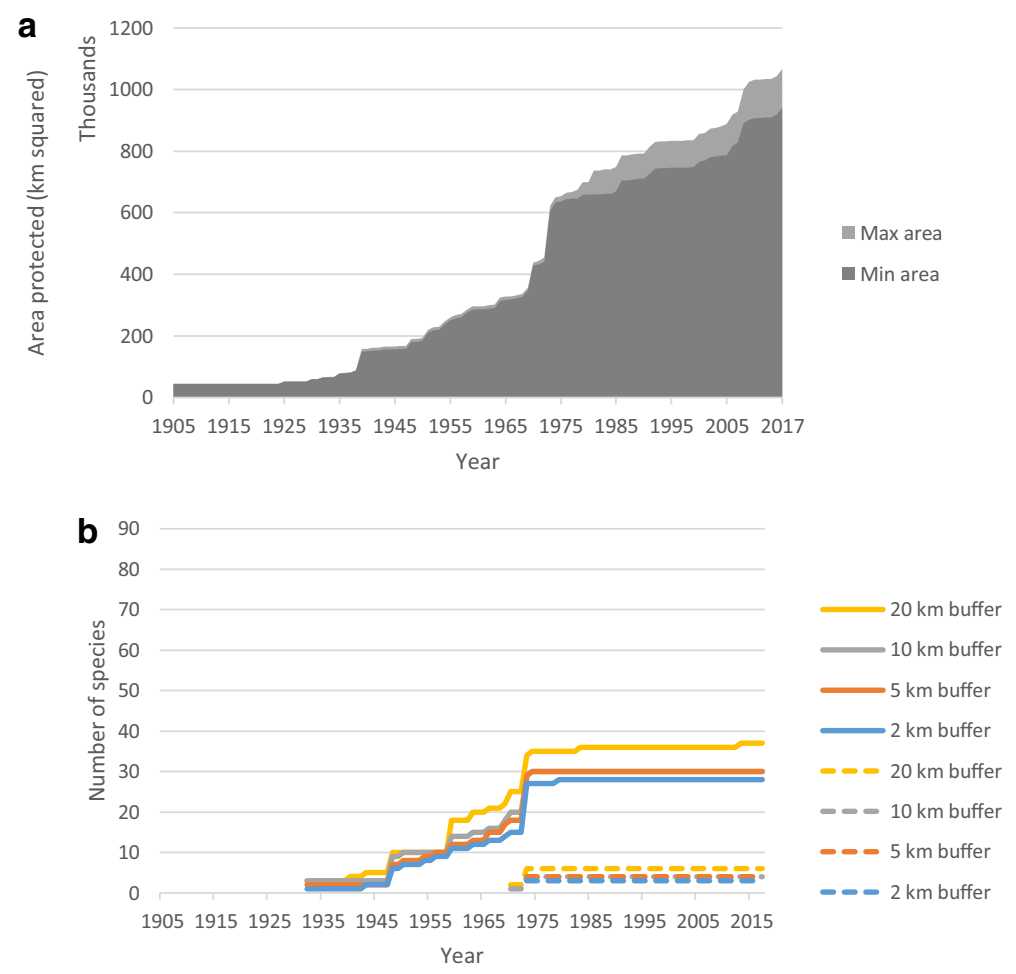

Fig. 6 Growth in PA coverage over time, across the countries where Horn of Africa Aloe occur (a) compared with number of Aloe species' ranges that overlap protected areas (b). Aloe species ranges were derived from occurrence points buffered at 2, 5, 10 and $20 \mathrm{~km}$ radius for all species (solid lines) and threatened species (dashed lines). In (a) the minimum ( $\mathrm{min}$ ) protected area (PA) coverage was calculated from all polygons in the PA dataset and the maximum (max) PA coverage was calculated by adding all polygons plus the buffered point layer for PAs that did not have spatial boundaries defined

species required protection of 25 additional patches totalling $542 \mathrm{~km}^{2}$ (Table A6b); the first ten of these patches are identified in Fig. 8b. In both analyses, the highest priority patch is the western limit of the Al Madow (Cal Madow) mountain range in Somalia, approximately $15 \mathrm{~km}$ north-west of Ceerigaabo (Erigavo), the capital city of the Sanaag region. In the best (i.e. least-area) scenario for protecting threatened Aloe species, half of the top ten patches were in Somalia. According to the WDPA dataset, there are 21 designated Wildlife Reserves and National Parks listed for Somalia. However, although the locations of these PAs were listed, the area was not reported, so buffers were not generated for any PA sites in Somalia. It is therefore possible that the ranges of some Aloe species overlap with the listed reserves and parks, but until a spatial boundary or estimate of area is added to these data, it is not possible to include these sites in the analysis.

The distribution of protected areas varies considerably across the Horn of Africa countries, with only Ethiopia meeting Aichi Target 11 with $17 \%$ protected, although South Sudan is approaching this level with $15 \%$ of land area protected (Table A7 in Supplementary Data). 


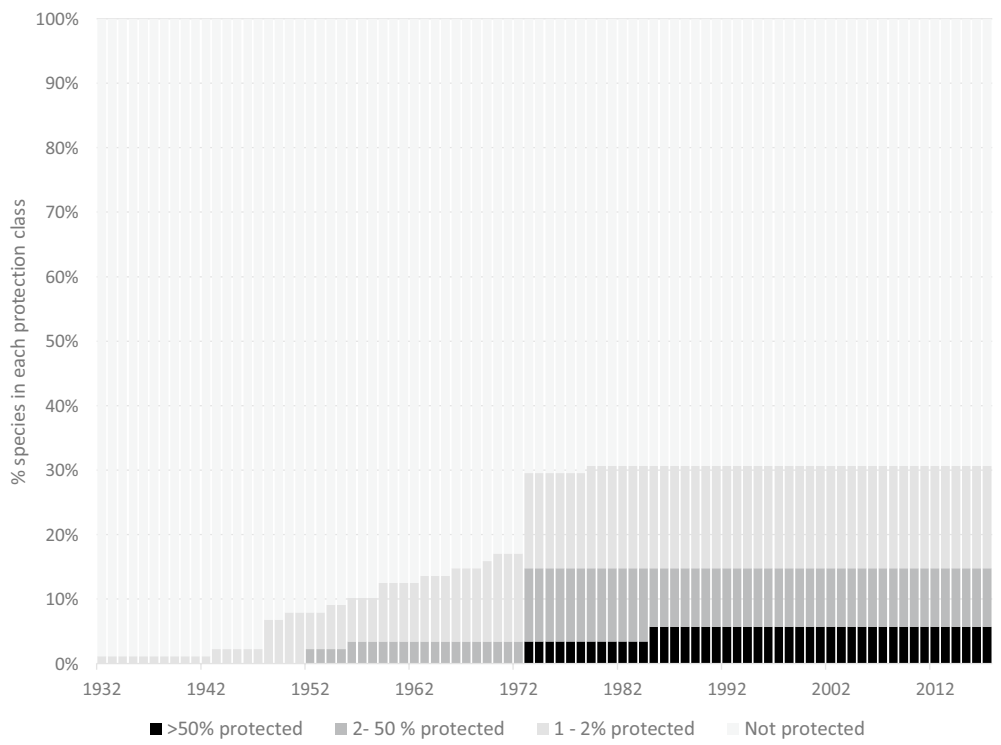

Fig. 7 Mean proportion of Aloe species ranges (based on $2 \mathrm{~km}$ buffer of points) that overlap with PAs from 1932 to 2017. For example, in 2017, 5\% of all Aloe species had at least 50\% of the range covered by a PA

\section{Representation of Horn of Africa Aloe in seed banks and botanic gardens}

Aloe species in the Horn of Africa are represented in multiple botanic gardens around the world (see Table A8 in Supplementary Material). Botanic Gardens hold at least one collection for 69 of the 88 species (78\%), leaving 19 species (22\%) without any representation in any botanic garden. Some species are particularly well represented, such as Aloe jucunda with 78 collections. Threat status does not appear to be a factor in choice of Aloe species for ex situ collection (Fig. 9). Only 14 (16\%) of the Aloe species have been collected for ex situ storage as part of the Millennium Seed Bank partnership (see Table A8 in supplementary material). These 14 seed-banked species represent $19 \%$ of the threatened species and $16 \%$ of non-threatened species (Table A9).

\section{Discussion}

Our results fill one of the last remaining regional gaps in knowledge of extinction risk status for the genus Aloe. We found that $39 \%$ of species in the genus Aloe from the Horn of Africa are threatened with extinction (35-45\% lower and upper bounds respectively to account for uncertainty of Data Deficient taxa). The major threats to Aloe species are the expansion and intensification of crop farming and livestock farming, but important additional threats include gathering of plants and the unintentional effects of logging and wood harvesting. Representation of ex situ Aloe in living collections is relatively high with $78 \%$ species represented by at least one collection. In contrast, only $16 \%$ of Aloe species are held in seed banks, limiting the scope for restoration efforts. Growth in PA coverage since 
Fig. 8 Maps illustrating the location of the top ten sites in order of priority ( 1 is highest priority) to capture all species (a), and all threatened species (b), with the minimum amount of additional PA. All sites are shown as blue patches and the existing PA network is shown with green polygons. A full list of sites is provided in Table A6 Supplementary Material

1970s has not been aligned with the distribution of Aloe species, especially for threatened species, with little or no current PA coverage for $\sim 70 \%$ of species. We demonstrate that a simple algorithm can be employed to identify areas to grow the PA network in an efficient way to achieve greater representation of species in PAs.

\section{Threats and extinction risk of Aloe in the Horn of Africa}

Even though all Aloe in the Horn of Africa have now been assessed and published on the IUCN Red List, our estimate of $39 \%$ threatened is uncertain because $10 \%$ of species were listed as Data Deficient (DD). The DD categorisation may inadvertently deprioritise species from much needed conservation attention as DD species are more likely to be threatened (Bland et al. 2015). To address this data gap, techniques have been developed based on machine learning that use life-history, threat and environmental data to predict threat status of Not Evaluated or Data Deficient species (Bland and Böhm 2016; Darrah et al. 2017). Reduction in Data Deficiency can also be achieved through additional botanical surveys, although this is dependent on resources and accessibility to under-explored sites.

We demonstrate that occurrence data, primarily derived from herbarium specimens, can be successfully used to generate Red List assessments. However, inherent bias in herbarium specimen collections can influence geographic range estimates such as EOO and AOO. The use of occurrence data and a $2 \times 2 \mathrm{~km}$ reference scale to calculate AOO was deemed appropriate here because Aloe in this region often have fragmented and dispersed distributions and therefore low AOO values are likely to be accurate. Furthermore, Aloe species are relatively conspicuous and have been targeted for botanical collection in this region, thereby reducing potential bias from under-sampling, although some areas remain unexplored. To reduce the error of mis-classifying species as threatened when they were simply under-represented by occurrence records, we used expert opinion derived from extensive fieldwork in the region, as well as knowledge of habitat preferences and elevation ranges. Incorporating expert opinion to estimate geographic ranges is susceptible to subjective bias if not elicited in a structured way (McBride et al. 2012), but is useful in reducing omission error rates from occurrence data (Rondinini et al. 2006) and can be used to document uncertainty in Red List assessments (IUCN Standards and Petitions Subcommittee 2014).

\section{Coincidence of protected areas and Horn of Africa Aloe distributions}

In contrast to our geographic range estimates for Red List assessment, we did not use expert opinion when investigating overlap of Aloe ranges with the protected area network. This is partly because the expert informed geographic ranges were not mapped, but also because even if these expert informed ranges were mapped, they may introduce commission errors (Rondinini et al. 2006), which in the context of protected areas could mean declaring a species as being protected when in fact there is no population within a protected area.

The pattern of steady growth in protected areas across the study region is consistent with global patterns (Butchart et al. 2012) and this is reflected in increasing levels of protection 

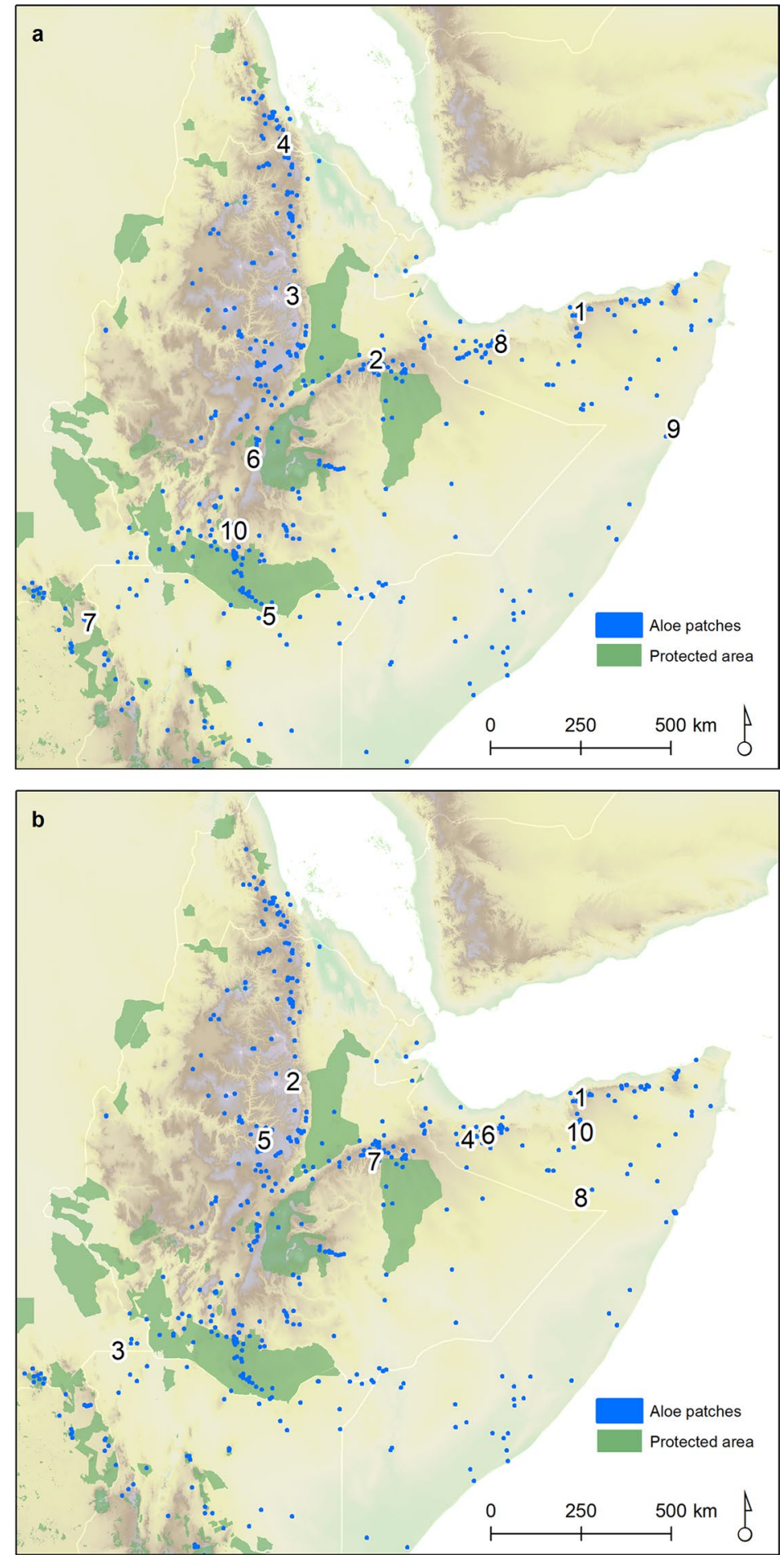


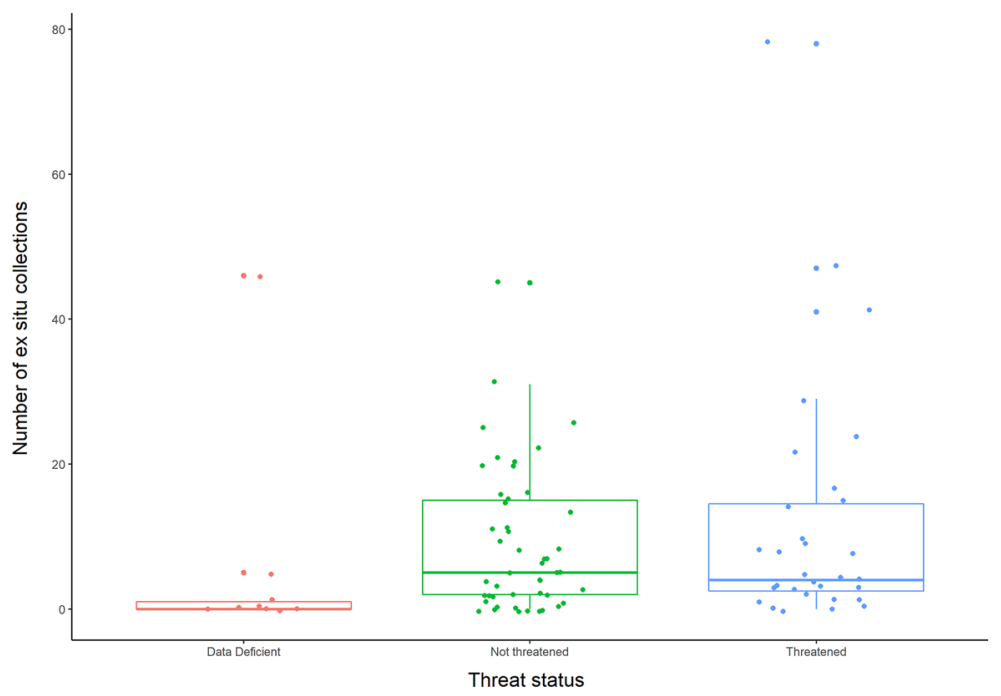

Fig. 9 Number of collections of Aloe in botanic gardens grouped by threat status: threatened, not threatened and data deficient. There was no significant difference between in number of ex situ collections for 'threatened' and 'not threatened' species $\mathrm{t}=-0.85, \mathrm{df}=43.06$, $\mathrm{p}$ value $=0.3987$

for Aloe species. However, the placement of protected areas established since the 1970s has added limited additional protection to Aloe species, both in terms of numbers of species protected and the proportions of ranges protected (Figs. 6, 7). This pattern is also reflected at the global scale when multiple biodiversity targets are considered (Butchart et al. 2012, 2015). The size of the buffer around Aloe point distributions, used to determine geographic ranges, did not change this overall pattern, but the number of species protected did increase by $32 \%$ when comparing $2 \mathrm{~km}$ to $20 \mathrm{~km}$ buffers for the current PA network. Di Marco et al. (2017) recommend using resolutions of 20-30 km, although this applies to the use of range maps rather than buffered point maps. For point occurrence records, the use of $2 \mathrm{~km}$ buffers is likely to produce a conservative estimate of range size, minimising commission errors.

\section{Options to extend the PA network to cover all Aloe species}

The greedy algorithm has been shown to perform well when applied to target-setting scenarios such as finding the highest number of species in the smallest area (Joppa et al. 2013). However, it may not always find the optimal solution because the 'greedy' path may miss a patch with a large number of unprotected species. The results of the greedy analysis represent a set of priority patches defined simply by species and area. An extension of this work could be to obtain data on planning costs, opportunities and difficulty in establishing new protected areas, and in this scenario a more comprehensive conservation planning tool like Marxan would be appropriate (Ball et al. 2009).

A major area of uncertainty in this analysis is the extent of protected area coverage in Somalia. Data on PAs in Somalia have recently been added to the WDPA dataset, but because only point data were provided, without reported area or year of establishment, they 
did not meet the requirements for inclusion in the analysis. Several patches from Somalia were identified as priorities for Aloe protection. The current lack of PA coverage for Somalia suggests it is not likely to meet its target for $17 \%$ coverage by 2020 . However, if Somalia were to officially designate and provide spatial boundaries for the sites already submitted to WDPA, it would be an important step towards the target and would allow the kind of gap analysis illustrated here. Political instability in Somalia has hampered the safeguarding of biodiversity through protected areas, although the need to improve management and enforcement are recognised in the most recent National Biodiversity Strategy and Action Plan (Ullah and Gadain 2016). In contrast, Ethiopia and South Sudan have grown protected areas steadily and may be more likely to establish new PAs even though South Sudan is close to meeting (15.5\%), and Ethiopia has already met (17.62\%), the target of $17 \%$ coverage by 2020 .

Another shortcoming of the greedy algorithm is that is does not consider resilience or redundancy in the PA network, rather is just looks for representation-i.e. all species protected in at least one patch. Representation may not be adequate for the long-term persistence of a species (Santini et al. 2014), but until more detailed data become available on distribution, dispersal ability and minimum viable population size for Aloe, representation remains the minimal target.

Underlying this analysis is the assumption that if protection is assigned, it will be effective in achieving the outcome of conserving biodiversity. Globally, although growth in PAs is in line with international targets, there are known shortfalls in the effective management of PAs due to capacity and funding gaps (Watson et al. 2014; Barnes et al. 2018) and this is also reflected in our study region (Ethiopian Biodiversity Institute 2015). The appropriate spatial location of PAs to ensure representation targets, as described here, needs to be supported with adequate resources to ensure effective management and governance.

The solutions we present to extend the existing PA network are also subject to the inherent historical biases typical with this kind of occurrence dataset such as accessibility (Reddy and Dávalos 2003; Kadmon et al. 2004; Meyer et al. 2016). Methods to quantify this bias (Stropp et al. 2016) and potentially correct for it (Schulman et al. 2007), will continue to be explored, but there is still merit in presenting the best available information on species distributions to gain opportunities for conservation, rather than incurring potential costs of waiting too long (Grantham et al. 2009).

\section{Representation of Horn of Africa Aloe in seed banks and botanic gardens}

Aloe species from the Horn of Africa are quite well represented in botanic gardens as live specimens, but not so well represented in ex situ seed bank collections. A possible caveat is that local botanic gardens may have living Aloe specimens that have not yet been captured in the BGCI Plant Search database. A recent review of ex situ collections in seed banks and botanic gardens suggests that although threatened species have been targets for collection, the species held in seed banks are more likely to be non-threatened (66\%) than threatened (34\%) (O'Donnell and Sharrock 2017). Our results show no clear preference for seed banking threatened Aloe species, and there are still considerable gaps, with 25 threatened species lacking a seed bank collection. 


\section{Conclusions}

The results presented here represent the new state of the art for assessment of conservation status of Aloe species in the Horn of Africa, thereby filling an important knowledge gap. Our results indicate that extinction risk is high, and protected area coverage is currently inadequate to represent all Aloe species, although this could be achieved with a relatively modest increase in protected area coverage using an optimisation approach. Similarly, analysis of ex situ conservation reveals gaps in species coverage, which we highlight as priorities to be addressed.

The data generated here on Aloe distributions and extinction risk assessments can also contribute to multi-taxon conservation prioritisation schemes, site-prioritisation schemes such as Important Plant Areas and Alliance for Zero Extinction Sites, and can support country-level biodiversity action plans and strategies. Ongoing monitoring and survey of populations will be an essential task to ensure re-assessment of conservation status is robust and to determine whether conservation gaps are being addressed.

Acknowledgements We would like to thank Craig Hilton-Taylor for co-ordinating the review and publication of the IUCN Red List assessments of aloes on the Red List website, include the review of some species. We also thank Henk Beentje on behalf of the East Africa Plant Red List Authority for additional reviews of assessments. SD would like to acknowledge the support from NUFU (Norway) for work on Aloes and Lilies, and the Carlsberg Foundation, Copenhagen for continued support for the study of the Ethiopian vegetation. Naomi Carvey provided data from the Millennium Seed Bank Data Warehouse.

Open Access This article is distributed under the terms of the Creative Commons Attribution 4.0 International License (http://creativecommons.org/licenses/by/4.0/), which permits unrestricted use, distribution, and reproduction in any medium, provided you give appropriate credit to the original author(s) and the source, provide a link to the Creative Commons license, and indicate if changes were made.

\section{References}

Amir HM, Grace OM, Wabuyele E, Manoko MLK (2019) Ethnobotany of Aloe L. (Asphodelaceae) in Tanzania. S Afr J Bot 122:330-335. https://doi.org/10.1016/J.SAJB.2019.01.038

Arponen A (2012) Prioritizing species for conservation planning. Biodivers Conserv 21:875-893. https ://doi.org/10.1007/s10531-012-0242-1

Bachman SP, Moat J, Hill A et al (2011) Supporting Red List threat assessments with GeoCAT: geospatial conservation assessment tool. Zookeys 150:117. https://doi.org/10.3897/zookeys.150.2109

Ball IR, Possingham HP, Watts ME (2009) Marxan and relatives: software for spatial conservation prioritization. Oxford University Press, Oxford

Barnes MD, Glew L, Wyborn C, Craigie ID (2018) Prevent perverse outcomes from global protected area policy. Nat Ecol Evol 2:759-762. https://doi.org/10.1038/s41559-018-0501-y

Bjorå CS, Wabuyele E, Grace OM et al (2015) The uses of Kenyan aloes: an analysis of implications for names, distribution and conservation. J Ethnobiol Ethnomed 11:82. https://doi.org/10.1186/s1300 2-015-0060-0

Bland LM, Böhm M (2016) Overcoming data deficiency in reptiles. Biol Conserv. https://doi. org/10.1016/j.biocon.2016.05.018

Bland LM, Collen B, Orme CDL, Bielby J (2015) Predicting the conservation status of data-deficient species. Conserv Biol 29:250-259. https://doi.org/10.1111/cobi.12372

Brooks TM, Mittermeier RA, Da Fonseca GAB et al (2006) Global biodiversity conservation priorities. Science 313:58-61

Brummitt NA, Bachman SP, Griffiths-Lee J et al (2015) Green plants in the red: a baseline global assessment for the IUCN sampled Red List Index for plants. PLoS ONE 10:e0135152. https://doi. org/10.1371/journal.pone.0135152 
Butchart SHM, Scharlemann JPW, Evans MI et al (2012) Protecting important sites for biodiversity contributes to meeting global conservation targets. PLoS ONE 7:32529. https://doi.org/10.1371/journ al.pone.0032529

Butchart SHM, Clarke M, Smith RJ et al (2015) Shortfalls and solutions for meeting national and global conservation area targets. Conserv Lett 8:329-337. https://doi.org/10.1111/conl.12158

Cardinale BJ, Duffy JE, Gonzalez A et al (2012) Biodiversity loss and its impact on humanity. Nature 486:59-67

Cardoso P, Erwin TL, Borges PAV, New TR (2011) The seven impediments in invertebrate conservation and how to overcome them. Biol Conserv 144:2647-2655. https://doi.org/10.1016/j.bioco n.2011.07.024

CBD (2010) X/17. Consolidated update of the global strategy for plant conservation 2011-2020

Ceballos G, Ehrlich PR, Barnosky AD et al (2015) Accelerated modern human-induced species losses: entering the sixth mass extinction. Sci Adv 1:1-5. https://doi.org/10.1126/sciadv.1400253

CITES-Secretariat (2016) CITES - convention on international trade in endangered species of wild fauna and flora. https://cites.org/. Accessed 26 Jan 2016

Collen B, Ram M, Zamin T, Mcrae L (2008) The tropical biodiversity data gap: addressing disparity in global monitoring. Mongabay.com. J Trop Conserv Sci 11:75-8875

Dahlberg A, Mueller GM (2011) Applying IUCN red-listing criteria for assessing and reporting on the conservation status of fungal species. Fungal Ecol 4:147-162. https://doi.org/10.1016/j.funec o.2010.11.001

Darbyshire I, Kordofani MAY, Farag I et al (2015) The plants of Sudan and South Sudan: an annotated checklist. Royal Botanic Gardens, Kew

Darbyshire I, Anderson S, Asatryan A et al (2017) Important plant areas: revised selection criteria for a global approach to plant conservation. Biodivers Conserv 26:1767-1800. https://doi.org/10.1007/ s10531-017-1336-6

Darkoh MBK (2003) Regional perspectives on agriculture and biodiversity in the drylands of Africa. J Arid Environ 54:261-279. https://doi.org/10.1006/jare.2002.1089

Darrah SE, Bland LM, Bachman SP et al (2017) Using coarse-scale species distribution data to predict extinction risk in plants. Divers Distrib 23:435-447. https://doi.org/10.1111/ddi.12532

Demissew S, Nordal I (2010) Aloes and other lilies of Ethiopia and Eritrea. Shama Books, Addis Ababa

Di Marco M, Watson JEM, Possingham HP, Venter O (2017) Limitations and trade-offs in the use of species distribution maps for protected area planning. J Appl Ecol 54:402-411. https://doi. org/10.1111/1365-2664.12771

Díaz S, Settele J, Brondízio E et al (2019) IPBES, summary for policymakers of the global assessment report on biodiversity and ecosystem services of the Intergovernmental Science-Policy Platform on Biodiversity and Ecosystem Services

ESRI (2017) ArcGIS Pro

Ethiopian Biodiversity Institute (2015) Ethiopia's national biodiversity strategy and action plan. Ethiopian Biodiversity Institute, Addis Ababa

Gaston KJ, Rodrigues ASL (2003) Reserve selection in regions with poor biological data. Conserv Biol 17:188-195. https://doi.org/10.1046/j.1523-1739.2003.01268.x

Goettsch B, Hilton-Taylor C, Cruz-Piñón G et al (2015) High proportion of cactus species threatened with extinction. Nat Plants. https://doi.org/10.1038/nplants.2015.142

Grace OM (2011) Current perspectives on the economic botany of the genus Aloe L. (Xanthorrhoeaceae). S Afr J Bot 77:980-987. https://doi.org/10.1016/j.sajb.2011.07.002

Grand J, Cummings MP, Rebelo TG et al (2007) Biased data reduce efficiency and effectiveness of conservation reserve networks. Ecol Lett 10:364-374. https://doi.org/10.1111/j.1461-0248.2007.01025.x

Grantham HS, Wilson KA, Moilanen A et al (2009) Delaying conservation actions for improved knowledge: how long should we wait? Ecol Lett 12:293-301. https://doi.org/10.1111/j.1461-0248.2009.01287.x

Hoffmann M, Brooks T, da Fonseca G et al (2008) Conservation planning and the IUCN Red List. Endanger Species Res 6:113-125. https://doi.org/10.3354/esr00087

Hooper DU, Adair EC, Cardinale BJ et al (2012) A global synthesis reveals biodiversity loss as a major driver of ecosystem change. Nature 486:105-108. https://doi.org/10.1038/nature11118

IUCN (2012) IUCN Red List categories and criteria: version 3.1, 2nd edn. IUCN, Gland

IUCN (2016a) A global standard for the identification of key biodiversity areas, version 1.0, 1st edn. IUCN, Gland

IUCN (2016b) Table 1: numbers of threatened species by major groups of organisms (1996-2016). http:// cmsdocs.s3.amazonaws.com/summarystats/2017-1_Summary_Stats_Page_Documents/2017_1_RL_ Stats_Table_1.pdf 
IUCN Standards and Petitions Subcommittee (2014) Guidelines for using the IUCN Red List categories and criteria. Version 11 (February 2014). Prep. by Stand. Petitions Work. Gr. IUCN SSC Biodivers. Assessments Subcomm. August 2008

Joppa LN, Visconti P, Jenkins CN, Pimm SL (2013) Achieving the convention on biological diversity's goals for plant conservation. Science 341:1100-1103. https://doi.org/10.1126/science. 1241706

Joppa LN, Butchart SHM, Hoffmann M et al (2016) Impact of alternative metrics on estimates of extent of occurrence for extinction risk assessment. Conserv Biol 30:362-370. https://doi.org/10.1111/ cobi. 12591

Kadmon R, Farber O, Danin A (2004) Effect of roadside bias on the accuracy of predictive maps produced by bioclimatic models. Ecol Appl 14:401-413. https://doi.org/10.1890/02-5364

Kehoe L, Romero-Muñoz A, Polaina E et al (2017) Biodiversity at risk under future cropland expansion and intensification. Nat Ecol Evol. https://doi.org/10.1038/s41559-017-0234-3

Klopper RR, Smith G, Crouch N et al (2013) Aloes of the world project: background and progress. In: XIXth AETFAT Congress, 26-30 April 2010, At Antananarivo, Madagascar, pp 332-336

Le Bras G, Pignal M, Jeanson ML et al (2017) The French Muséum national d'histoire naturelle vascular plant herbarium collection dataset. Sci Data 4:170016. https://doi.org/10.1038/sdata.2017.16

Li J, Gale SW, Kumar P et al (2018) Prioritizing the orchids of a biodiversity hotspot for conservation based on phylogenetic history and extinction risk. Bot J Linn Soc 186:473-497. https://doi.org/10.1093/botli nnean/box084

Lilles $\emptyset \mathrm{JB}$, van Breugel P, Kindt R et al (2011) Potential natural vegetation of Eastern Africa (Ethiopia, Kenya, Malawi, Rwanda, Tanzania, Uganda and Zambia), vol 1. University of Copenhagen, Copenhagen

Luke Q, Bangirinama F, Beentje H et al (2014) Progress in assessing the conservation status of Eastern African plants. In: Bytebier B, Muasya AM, Bellstedt DU (eds) Abstracts of the XXth AETFAT congress: biodiversity of African plants: challenges in a changing world, 52nd edn. Scripta Botanica Belgica, p 248

McBride MF, Garnett ST, Szabo JK et al (2012) Structured elicitation of expert judgments for threatened species assessment: a case study on a continental scale using email. Methods Ecol Evol 3:906-920. https://doi.org/10.1111/j.2041-210X.2012.00221.x

McCarthy DP, Donald PF, Scharlemann JPW et al (2012) Financial costs of meeting global current spending and unmet needs. Science 338:946-949

Meyer C, Kreft H, Guralnick R, Jetz W (2015) Global priorities for an effective information basis of biodiversity distributions. Nat Commun 6:8221. https://doi.org/10.1038/ncomms9221

Meyer C, Weigelt P, Kreft H (2016) Multidimensional biases, gaps and uncertainties in global plant occurrence information. Ecol Lett. https://doi.org/10.1111/ele.12624

Mittermeier RAA, Gil PR, Hoffman M et al (2004) Hotspots revisited: earth's biologically richest and most endangered ecoregions. CEMEX and Agrupación Sierra Madre, Mexico

Moat J (2007) Conservation assessment tools extension for ArcView 3.x, version 1.2. GIS Unit, Royal Botanic Gardens, Kew

Myers N, Mittermeier RA, Mittermeier CG et al (2000) Biodiversity hotspots for conservation priorities. Nature 403:853-858. https://doi.org/10.1038/35002501

Newbold T, Tittensor DP, Harfoot MBJ et al (2018) Non-linear changes in modelled terrestrial ecosystems subjected to perturbations. https://doi.org/10.1101/439059

O'Donnell K, Sharrock S (2017) The contribution of botanic gardens to ex situ conservation through seed banking. Plant Divers 39:373-378. https://doi.org/10.1016/J.PLD.2017.11.005

R Core Team (2016) R: a language and environment for statistical computing. R Core Team, Vienna

Raimondo D, Von Statden L, Foden W et al (2009) Red List of South African plants. Strelitzia 25:668

Rakotoarinivo M, Dransfield J, Bachman SP et al (2014) Comprehensive red list assessment reveals exceptionally high extinction risk to Madagascar palms. PLoS ONE. https://doi.org/10.1371/journ al.pone. 0103684

Rakotoarisoa SE, Klopper RR, Smith GF (2014) A preliminary assessment of the conservation status of the genus Aloe L. in Madagascar. Bradleya 32:81-91

Reddy S, Dávalos LM (2003) Geographical sampling bias and its implications for conservation priorities in Africa. J Biogeogr 30:1719-1727. https://doi.org/10.1046/j.1365-2699.2003.00946.x

Ricketts TH, Dinerstein E, Boucher T et al (2005) Pinpointing and preventing imminent extinctions. PNAS 102:18497-18501. https://doi.org/10.1073/pnas.0509060102

Rivers MC (2017) The global tree assessment: Red Listing the world's trees. BGJournal 14:16-19

Rivers MC, Taylor L, Brummitt NA et al (2011) How many herbarium specimens are needed to detect threatened species? Biol Conserv 144:2541-2547. https://doi.org/10.1016/j.biocon.2011.07.014 
Rondinini C, Wilson KA, Boitani L et al (2006) Tradeoffs of different types of species occurrence data for use in systematic conservation planning. Ecol Lett 9:1136-1145. https://doi.org/10.111 $1 / \mathrm{j} .1461-0248.2006 .00970 . x$

Salafsky N, Salzer D, Stattersfield AJ et al (2008) A standard lexicon for biodiversity conservation: unified classifications of threats and actions. Conserv Biol 22:897-911. https://doi.org/10.111 1/j.1523-1739.2008.00937.x

Santini L, Di Marco M, Boitani L et al (2014) Incorporating spatial population structure in gap analysis reveals inequitable assessments of species protection. Divers Distrib 20:698-707. https://doi. org/10.1111/ddi.12198

Schulman L, Toivonen T, Ruokolainen K (2007) Analysing botanical collecting effort in Amazonia and correcting for it in species range estimation. J Biogeogr 34:1388-1399. https://doi.org/10.111 $1 /$ j.1365-2699.2007.01716.x

Stropp J, Ladle RJ, Malhado M et al (2016) Mapping ignorance: 300 years of collecting flowering plants in Africa. Glob Ecol Biogeogr 25:1085-1096. https://doi.org/10.1111/geb.12468

Stuart SN, Wilson EO, McNeely JA et al (2010) Ecology. The barometer of life. Science 328:177

Thiers BM (2015) Index Herbariorum: a global directory of public herbaria and associated staff. New York Botanical Garden, New York

Tierney M, Almond R, Stanwell-Smith D et al (2014) Use it or lose it: measuring trends in wild species subject to substantial use. ORYX 48:420-429. https://doi.org/10.1017/S0030605313000653

Ullah S, Gadain H (2016) National biodiversity strategy and action plan (NBSAP) of Somalia

UNEP/CBD (2010) The strategic plan for biodiversity 2011-2020 and the Aichi biodiversity targets. In: $\mathrm{UNEP} / \mathrm{CBD} / \mathrm{COP} / \mathrm{DEC} / \mathrm{X} / 2$. https://www.cbd.int/decision/cop/?id=12268

UNEP-WCMC and IUCN (2018) The world database on protected areas (WDPA). UNEP-WCMC and IUCN, Cambridge

Urban MC (2015) Accelerating extinction risk from climate change. Science (80-) 348:571-573. https:// doi.org/10.1126/science.aaa4984

Venter O, Fuller RA, Segan DB et al (2014) Targeting global protected area expansion for imperiled biodiversity. PLoS Biol 12:1001891. https://doi.org/10.1371/journal.pbio.1001891

Venter O, Sanderson EW, Magrach A et al (2016) Sixteen years of change in the global terrestrial human footprint and implications for biodiversity conservation. Nat Commun 7:12558. https://doi. org/10.1038/ncomms 12558

Wabuyele E, Bjorå CS, Nordal I, Newton LE (2006) Distribution, diversity and conservation of the genus Aloe in Kenya. J East Afr Nat Hist 95:213-225. https://doi.org/10.2982/0012-8317(2006)95\%5b213 :ddacot\%5d2.0.co;2

Waldron A, Mooers AO, Miller DC et al (2013) Targeting global conservation funding to limit immediate biodiversity declines. Proc Natl Acad Sci USA 110:12144-12148. https://doi.org/10.5061/dryad.p69t1

Watson JEM, Dudley N, Segan DB, Hockings M (2014) The performance and potential of protected areas. Nature 515:67-73

Wilkin P, Suksathan P, Keeratikiat K et al (2013) A new species from Thailand and Burma, Dracaena kaweesakii Wilkin \& Suksathan (Asparagaceae subfamily Nolinoideae). PhytoKeys 26:101-112. https:// doi.org/10.3897/phytokeys.26.5335

Publisher's Note Springer Nature remains neutral with regard to jurisdictional claims in published maps and institutional affiliations.

\section{Affiliations}

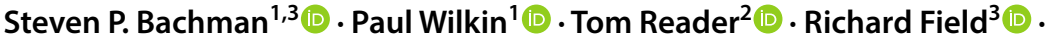 Odile Weber $^{4}\left(\mathbb{D} \cdot\right.$ Inger Nordal $^{5} \cdot$ Sebsebe Demissew ${ }^{1,6}$}

Paul Wilkin

p.wilkin@kew.org

Tom Reader

Tom.Reader@nottingham.ac.uk

Richard Field

Richard.Field@nottingham.ac.uk 
Odile Weber

Odile.WEBER@mnhn.lu

Inger Nordal

inger.nordal@mn.uio.no

1 Royal Botanic Gardens, Kew, Richmond, Surrey TW9 3AE, UK

2 School of Life Sciences, University of Nottingham, Nottingham NG7 2RD, UK

3 School of Geography, University of Nottingham, Nottingham NG7 2RD, UK

4 Recherche et Collections, Musée National d'Histoire Naturelle, 25 rue Münster, 2160 Luxembourg, Luxembourg

5 Department of Biology, University of Oslo, P.O. Box 1045, Blindern, 0316 Oslo, Norway

6 National Herbarium, College of Natural Sciences, Addis Ababa University, P.O. Box 3434, Addis Ababa, Ethiopia 